\title{
FOCUSING INFORMATION SYSTEMS POST-GRADUATE RESEARCH PROJECTS
}

\author{
Gail Ridley \\ Information Systems Group \\ Department of Computer Science \\ University of Tasmania \\ GPO Box 252C Hobar Tasmania 7001 \\ Email: Gail.Ridley@cs.utas.edu.au
}

\begin{abstract}
This paper reports on an investigation of mechanisms that assist Information Systems post-graduate research students to focus their projects.

An evaluation is presented of the experiences of Information Systems research students in focussing their research projects based on a survey conducted of students who participated in two of the first three Information Systems doctoral consortia to be held in Australia. The survey sought to determine whether a doctoral consortium or 'systematic expert review' is the most valuable mechanism for focussing a research proposal.

Systematic expen review was considered by the students to be more effective than the doctoral consontium process for the purpose of focussing their research project proposals.
\end{abstract}

\section{INTRODUCTION}

Recently criticism has been levelled at some practices and achievements of research post-graduate education and supervision in Australia. Against this background Information Systems (IS) and other responsive research communities have recently adopted and implemented the post-doctoral consortium process. It is unclear how much evaluation of the doctoral consortium mechanism took place before it was instituted. Having participated in doctoral consortia and systematic expert review, the author was motivated to determine how common it was for post-graduate students to take part in the latter, and which of the two strategies was considered by postgraduate students to be the most effective for focussing a research project. Another motivation for the investigation was to learn of other methods that the post-graduate students had used to focus their projects.

It is assumed that one of the most difficult phases of a research higher degree is the period taken to focus on a research question. As Information Systems is a relatively recent and still developing discipline where traditions and theory are being established (Farhoomand 1992; Miller 1993), this must be particularly so.

The appropriate methodologies and content of IS are both under debate. Shanks et al. (1993) report that some IS researchers argue that interpretivism is the preferred framework. Keen (1991) observes however, that the positivist perspective dominates IS journals. Methodological pluralism is advocated by Galliers (1992). Such diverse views suggest that knowledgeable review of a student proposal is warranted.

Because of IS's interdisciplinary nature, there are few clearly defined boundaries (Shanks $e t$ al. 1993). Such a characteristic may make it difficult for novice researchers to conduct literature searches and find someone with sufficient background in the knowledge domain to review a research proposal.

However, as IS is still an emerging discipline (Miller, 1993), opportunities for contact with active IS researchers may be limited. Even a cursory examination of the 1996 Asia Pacific Directory of Information Systems Researchers reveals a wide range in the faculty and departmental placement of IS researchers in Australia. Australian researchers who identify with the IS field work within departments or schools as disparate as: School of Environmental and Information Science, Department of Computer Science and Computer Engineering, Graduate School of Management, Department of Information Management and Marketing and Department of Information Systems. Where university teaching and research in IS are conducted within a larger and more dominant field with different paradigms such as computer science or management, and Information Systems researchers are a small minority, greater difficulty in observing IS researchers at work may be anticipated. Such characteristics of IS may make it difficult for a research student to be able to select a focus and plan a project with confidence, particularly in geographically isolated areas or where a proposed project is in a less dominant knowledge domain.

Australian post-graduate students commencing research frequently spend lengthy periods trying to determine a topic and methodology. However, in American PhD programmes, the emphasis on graduate coursework before starting a research project allows students 'to develop research proposals systematically...' (Higher Education Council, 1990). Due to differences in the structure of Australian PhD programs, it is argued in this paper that Australian post-graduate research students have special requirements in order to determine the scope and approach of their project when compared to their American counterparts. These special requirements may be met by strategies such as those proposed in this paper. 
Cullen et al. (1994) have identified the need to formulate a feasible topic as being significant to the successful completion of a PhD project. Assistance from experienced academics at the time of deciding on a research topic and writing a proposal may be critical to the ultimate success of the project. Locke and Spirduso (1976) firmly discount the idea that it is 'vaguely immoral to seek assistance in preparing a proposal'. This paper assumes that such help is pivotal to the outcome of the research project and is primarily concerned with just one aspect of supervision, the provision of opportunities to help the student select and focus a research proposal.

\section{BACKGROUND}

\section{Approaches to supervision}

The report, Establishing Effective PhD Supervision, written for the (Australian) Department of Employment, Education and Training (DEET) by Cullen et al. 1994, states that the American PhD system makes greater use of a panel of supervisors and thesis advisers than does the Australian system. In Australia, as in some other nations, a single supervisor (or sometimes a supervisor and associate supervisor) is more common. However, the same authors state that 'no one supervisor can be expected to provide all that is needed all the time to different students.' This points to an inadequacy in the traditional means of supervising Australian postgraduate research projects which may translate into a difficulty for the student in formulating a project.

One possible solution to achieve effective supervision is proposed in the same report. It is recommended that supervisory panels be established to give students access to a wider range of expertise and skills. Cullen $e t a l$. also state in the same report that '...there is a need to [...] restructure practice to ensure that responsibility for quality is co-ordinated'. It seems likely then, that where a student's proposal is exposed to other researchers for feedback, its quality will be greater.

Cullen $e$ al. recommend that a study be made of other strategies to restructure graduate education. It is proposed that the mechanisms examined in this paper will assist research students to determine an appropriate topic. As discussed earlier, the process of determining an appropriate topic is related to the successful completion of a $\mathrm{PhD}$ project. The analysis and findings reported in this paper contribute to satisfying the information need identified by Cullen $e t$ al.

\section{Student contact with other researchers}

Cullen et al. (1994) state that Australian graduate programs generally have less students than those in the United States of America. It is likely, then, that there is less appropriate expertise to draw upon within Australian university departments to assist the student, and as a consequence, it could be argued that there is a need for greater contact with academics from relevant departments elsewhere.

Recognition was given to the need for greater contact between universities when the Higher Education Council in Australia recommended in 1990 that higher education institutions examine student research proposals and 'develop formal and informal links with other institutions' for mutual benefit. However, studies by Powles (1988) and Cullen et al. (1994) indicate that a significant to majority proportion of post-graduate students have little contact with staff and students at other institutions in order to obtain feedback on their research.

The findings of a survey of students and supervisors conducted by Cullen $e$ t al. (1994) give 'sources of critical assistance' used by $\mathrm{PhD}$ students. Only $22 \%$ obtained critical assistance from academics in the same department, and just $8 \%$ obtained the same kind of help from academics elsewhere.

In another Australian study, Powles (1988) found that 55\% of students had received no advice from staff in other departments and $36 \%$ had no advice from academic staff other than their supervisor, resulting in intellectual isolation for many. Powles also found that $31 \%$ of students enrolled for four years or more had not attended one local, state or national meeting or conference, a startling indication of limited contact with research students and academics from outside their own department. These statistics give credence to Cullen $e t$ al.'s (1994) plea to '...go beyond individual supervisory interactions' for post-graduate students.

\section{Mechanisms to assist supervision}

In the DEET report, Supervising Higher Degree Research Students, Parry and Hayden (1994) state that consensual approaches to determine that a post-graduate thesis is acceptable are much more useful than 'attempting to define in advance the acceptable characteristics of theses, against which an individual student's work could be judged.' Such 'consensual approaches' include presenting work at conferences and seminars, and publishing to give both supervisors and students confidence that acceptable progress is being made. It can 
be seen, then, that obtaining feedback on a student's work from outside the student's department can be proposed on the grounds of increased efficiency in addition to the advantages regarding quality.

Powles (1988) found that ' $47 \%$ of $\mathrm{PhD}$ students had not been required to submit a written progress report and $48 \%$ had not had to give an oral progress report of a formal type during their candidature.' It is likely that such written and oral progress reports would be reviewed by other academics in addition to the student's supervisor, broadening the expertise and skills base of those reviewing the student's project. However, despite the belief by $86 \%$ of the students surveyed in the Powles study that "the oral reports [were] "very useful" or "somewhat useful" ', almost half of the students surveyed had not had this opportunity.

\section{Doctoral Consortia}

A recent phenomenon to Australia (Conrad, 1991), designed to assist in the definition of post-graduate research projects, is the doctoral consortium. Both doctoral and research masters students have participated in doctoral consortia. Due to its recent introduction, there is little literature available. Doctoral consortia are better established outside Australia, particularly in Europe and the United States, where their function may be different. In Australian doctoral consortia, conference organisers group students before matching with one or more expert researchers in the area to review the research proposals. Both specific responses to the individual student and general advice to the group are usually offered.

The doctoral consortium was first launched in Australia with marketing PhD students at the Inaugural Australia and New Zealand Doctoral Consortium in March 1991 (Conrad, 1991). Since then they have been organised by the Accounting Association of Australia and New Zealand Conference (AAANZ) and the Department of Accountancy at the University of Wollongong and in the area of management accounting at the University of New South Wales (Leech, S. 1994, pers. comm., December).

The process has been applied more recently to the IS field in Australia, although consortia have been held in conjunction with the most recent International Conferences in Information Systems. The second and third Australian IS doctoral consortia were held in conjunction with two major conferences in 1994, at which the author was present.

\section{Other Mechanisms}

Parry and Hayden (1994) recommend that departments 'provide mechanisms whereby students are actively encouraged to participate in intellectual exchange with other scholars'. They review strategies to expose students' work to other scholars, including the presentation of work in progress at departmental seminars to provide students with feedback from students and academic staff of the department.

It is clear from the literature that there is a need for mechanisms that will broaden the provision of feedback on the students' work. Systematic expert review of post-graduate proposals may be another method of achieving the same objective. Such reviews involve a deliberate strategy of obtaining detailed and specific feedback in a sequential fashion from researchers familiar with the methodology or knowledge domain of the research proposal. Such researchers may work within or outside of the field of IS, and may be found among academics other than the student's supervisor/s within the same department, elsewhere in the same university, or at universities within and outside the country.

\section{STUDY METHODOLOGY}

The study objectives were to determine the value of the doctoral consortium from the post-graduate students' perspective in helping focus their research proposals. In addition, the investigation sought to learn whether the research proposals were reviewed by anyone other than the supervisor/s and the consortium facilitators, and the value of the experience for focussing the project. A final objective was to compare the value of doctoral consortium participation with other forms of non-supervisor review.

A largely quantitative approach was used for the study, but one that has been supported by qualitative data in order to validate the findings and to enrich the data in a way that would not have been possible had a strictly positivist epistemology been adopted (Jick, 1983). While quantitative analysis was employed, 'enumerative induction' has been used rather than the 'the more elaborate form of statistical induction in which probability theory is involved' (Mitchell 1983). In enumerative induction 'the characteristics of a class of phenomena are established ... by listing them' (Mitchell 1983). As the nature of the study was exploratory, it was considered that a combination of descriptive statistical analysis and qualitative investigation would be better suited to an initial investigation than use of inferential statistics. Sophisticated statistical analysis would have been inappropriate considering the objectives of the study and the nature of the data sought. 
A survey was the obvious method for contacting participants to obtain their perspective. Use of personal or telephone interviews would have been expensive and difficult as the research students were dispersed across Australia and New Zealand. Because of the nature of their discipline, all the subjects were likely to be familiar with, and have access to a computer and internet facilities. As a result, and because it was immediate and inexpensive, an emailed survey was chosen.

The emphasis of this paper is to examine strategies used to focus a research project. For this

reason, and as research masters students and $\mathrm{PhD}$ students were not segregated at the doctoral consortia and the numbers in both groups were not large enough to be independently representative, the responses from the two groups were not differentiated.

The two conferences with their affiliated doctoral consortia were chosen because they were the second and third IS doctoral consortia to have been held in Australia at the time that this paper was written. It was decided not to survey participants of the first IS doctoral consortia to allow for the refinement of the first iteration of the process.

Not all respondents had participated in expert review and where they had, the process had not been uniform. For this reason it was decided that the respondents would be asked to detail the advantages and disadvantages of the doctoral consortium, but not for systematic expert review.

The study subjects were 39 participants of the doctoral consortium that was held in association with the 5 th Australasian Conference on Information Systems (ACIS'94) as well as 18 participants of the doctoral consortium held with the International Federation for Information Processing Technical Committee 8 Open Conference on Business Process Re-engineering, 1994 Information Systems Intemational Working Conference (IFIP TC8AUS) at the Gold Coast, Australia in May 1994. The majority of the post-graduate attendees were enrolled at universities in Australia, and six participants travelled from New Zealand.

After initial piloting, an emailed questionnaire was developed that posed four questions. The first question asked the students to list the advantages and disadvantages of the doctoral consortium process for them personally. The second question used a five point Likert scale graduated from strongly agree to strongly disagree for the student to indicate the value of the doctoral consortium in helping to focus their research. The third question asked whether the student's research proposal had been reviewed by anyone other than their supervisor or consortium facilitators, and requested comments on the value of the experience for focussing the project. The last question required the respondent to state and compare the value of any form of review of their research proposal (excluding supervisor review) against participation in the doctoral consortium.

The questionnaire asked for some data that was designed to be analysed quantitatively, using 'enumerative' rather than 'statistical' deduction (Mitchell, 1983). Other open-ended questions that were designed to broaden understanding of the topic were subjected to content analysis. These responses were listed and clustered into groups to permit analysis. In this way, phrases were extracted that gave support to the quantitative data or enriched an understanding of the respondents. Some of this material has been included in the Results section that follows.

\section{RESULTS}

Of the 57 doctoral consortium participants surveyed, 37 responses were received, a return rate of $65 \%$. This figure includes two students who participated in both doctoral consortia. As the same questions were used for each conference, these two students were surveyed only once. If the two students had been asked to complete two identical questionnaires, it is likely that their responses to the second questionnaire would have been influenced by the experience of completing the same questionnaire earlier. Consequently, the responses from these two students were counted twice as the students were part of both conference groups. As over 30 questionnaires were returned by participants at the two doctoral consortia and no generalisations were made from the two subgroups, the responses were taken as being representative of the range of participants at the two consortia. This approach is consistent with that recommended by Roscoe (1975).

\section{Other mechanisms used for focussing a research proposal}

Many of the post-graduate students recommended mechanisms other than doctoral consortium participation that they had used to help focus their research proposal. These mechanisms are summarised in Table 1. By far the most popular of these mechanisms is expert review (ie to have academics other than their supervisor review their proposal). Doctoral consortia are not included in the table as all the students surveyed had participated at least once.

The next most popular mechanism was to present papers and seminars. Three students stated that discussion of the research project with staff was helpful. Such staff may be located in the student's department of enrolment, 
or with post-graduates who were also academics elsewhere, at the student's workplace. Two students wrote of the value of submitting papers to conferences, while the same number suggested that discussion with other students working in similar areas was of use.

One student identified the value of the 'panel meeting' approach, also referred to by another student as a trial consortium. In this arrangement a panel consisting of the supervisor, external supervisor (if relevant) and another person external to the student's department listened, reviewed and criticised the student's research, focussing on monitoring and support.

\begin{tabular}{|l|c|}
\hline Mechanisms Used & Number Of Responses \\
\hline Expert review & 16 \\
\hline Presenting seminars, papers & 5 \\
\hline Discussion with staff & 3 \\
\hline Submitting papers to conferences & 2 \\
\hline Discussion with other students & 2 \\
\hline Trial doctoral consortium (ie panel meeting) & 2 \\
\hline Applying for a faculty grant in similar area & 1 \\
\hline Preparing submissions for Ethics Committee & 1 \\
\hline Talking over research with friends & 1 \\
\hline
\end{tabular}

Table 1

Mechanisms Used for Focussing Research Proposal as Suggested by Research Students. More than one response was possible. Not all students suggested other mechanisms to heip focus their project.

Three students suggested one of each of the following: where a student was employed as an academic, applying for a faculty grant in an area related to her post-graduate research and getting feedback on the application, preparing a submission for the university's Ethics Committee and talking over the research with friends.

\section{Strengths of doctoral consortia}

Many advantages of the doctoral consortium process were identified by the participants. The most popular of these are summarised in Table 2.

\begin{tabular}{|l|c|}
\hline Main Strengths Of Doctoral Consortia & Number Of Responses \\
\hline Social and academic interaction & 19 \\
\hline Independent appraisal by peers \& researchers & 17 \\
\hline Focus on method & 8 \\
\hline Exposure to other research projects & 8 \\
\hline Support for common problems & 6 \\
\hline
\end{tabular}

Table 2

Main Strengths of Doctoral Consortla es Identified by Research Students Surveyed. More than one response to the question was possible.

Nineteen of the post-graduate students wrote of the strengths of being able to network with others working in similar areas through social and academic interaction. Another strength identified by seventeen of the consortium participants was the opportunity for critical, independent appraisal by peers and experienced researchers, particularly regarding research methods. More specifically, the opportunity to be able to focus on method was mentioned by eight students. Eight of the participants found exposure to other research projects of value, while six students stated that they appreciated the support for common problems that the consortium provided.

\section{Weaknesses of doctoral consortia}

The disadvantages of the doctoral consortium mentioned by the participants were more disparate than the stated advantages. A lengthy list of disadvantages suggested only once has been omitted for brevity. The main disadvantages are summarised in Table 3. 


\begin{tabular}{|l|c|}
\hline Main Weaknesses Of Doctoral Consortia & Number Of Responses \\
\hline Limitations in management of sessions & 8 \\
\hline Limitations in facilitation of groups & 8 \\
\hline Size of groups too large & 5 \\
\hline Insufficient time for feedback & 5 \\
\hline Research area too broad within groups & 4 \\
\hline
\end{tabular}

Table 3

Main Weaknesses of Doctoral Consortia as Identified by Research Students Surveyed

Eight students made comments relating to poor management of the sessions, such as 'one project dominated' and 'my facilitator was from my university'. Eight students commented negatively on the quality of the facilitation, with statements such as 'facilitator's review superficial [sic] as insufficient time for them to become familiar with your work' and 'facilitators weak in dealing with students, especially mature students, nearly all of whom were lecturers'. Five of the students stated that the size of the groups had been too large and another five considered that there had not been enough time for feedback. Four participants wrote that the areas of research had been too broad within the groups, both in terms of content and method, so that it was hard to maintain the interest of the other participants.

\section{Comparison of doctoral consortia and systematic expert review}

Some students were critical of the match between other students and the reviewers to their own work in the doctoral consortium they had attended. One student commented, 'Ideally, the student should be able to determine beforehand which student's work is most relevant to them and be grouped accordingly. Secondly, they should have more say in picking their reviewer - some reviewers can obviously input more ideas in a given field than other reviewers.'

In comparison, feedback from expert review was considered to have greater relevance to the student. One student commented that expert review was of more benefit as 'the reviewers had more expertise in my field and [...] a better understanding of what I was trying to do. Secondly, comments were made that applied to each individual's work...'. A similar view was communicated by another student in the statement, expert review has '...been more benefit than the doctoral consortium. This is particularly true if one considers the cost benefit relationship. Other sources are naturally one-on-one and therefore have the potential to being [sic] more productive or targeted.'

Several students saw doctoral consortia and expert review as fulfilling different roles. A comment that exemplifies this view is, 'The expert review evaluation was of more value because they were able to spend more time on looking at the content of my work. The focus at the doctoral consortium was more on research method.' Another student wrote, expert review was '...more valuable because comments made were more critical. [The comments] served to focus attention on specific strengths and weaknesses. [It] would be fair to say that the doctoral consortium did serve to highlight the general issues and therefore gave a good base for the comments from the [expert review ...] which came at a later date'. A third student summarised this perspective by writing that expert review and 'doctoral consortia are different, both are beneficial but for different reasons.' When the students were asked if the doctoral consortium had been of value in helping them focus the research proposal, 23 (62\%) agreed with the statement (ten strongly), while only eight (22\%) disagreed with it (two strongly disagreed). The discrepancy in the total represents the students who were uncertain.

Some of the participants of the two doctoral consortia had their research proposal reviewed by researchers other than their supervisor/s or the facilitators at the doctoral consortium. When this group was asked about the value of expert review all thirteen who answered the question were positive. This totally positive response must be contrasted with the $62 \%$ response that participation in the doctoral consortium had been of value.

When asked to evaluate the most effective focus mechanism, twelve students had taken part in both expert review and a doctoral consortium and stated a preference. Of these, nine preferred expert review while only three preferred the doctoral consortium process.

\section{DISCUSSION OF RESULTS}

The student preference for expert review to help focus a research proposal is revealed by the survey. During systematic expert review, students have contact with a range of academics over a long period to develop the proposal. One student referred to the ongoing nature of systematic expert review when he wrote, 'The whole 
project has evolved over time. Each individual, at various stages, helped shaped [sic] my thoughts about the project.'

As only two students enrolled in both doctoral consortia, evidence from the survey suggests that once a student has participated in a doctoral consortium, enrolment in future consortia is unlikely.

Eighteen or $53 \%$ of the students had not had their proposal reviewed by anyone other than their supervisor/s or doctoral consortia facilitators, either from inside their department or outside. It may be that those having experienced expert review feel less need to attend a doctoral consortium. However, this explanation is not supported by studies by Powles (1988) and Cullen et al. (1994) of students' general recourse to non-supervisor review of research proposals.

Cullen et al.'s (1994) findings that $22 \%$ of the population of the students surveyed at an Australian university obtained 'critical assistance' from academics in the same department, and $8 \%$ obtained the same kind of assistance from academics outside their department are considerably lower than the results obtained in this study. Contrary to the conjecture of the previous paragraph, students participating in a doctoral consortium may be more likely to seek outside assistance to focus their project. The nature of IS itself may also encourage students to obtain outside assistance. These factors may explain the higher proportion of students in this study who sought a review of their proposal than in the Cullen study.

Powles' (1988) findings may provide some support to the suggestion that the group surveyed in the current study may be more likely to seek assistance from academics other than their supervisors. He found that more than $30 \%$ of PhD students surveyed enrolled for four years or over had not attended a conference. As the two doctoral consortia were held in association with a conference, and the great majority of the students attending one of the consortia also attended the conference, the students captured in this survey do not fit the category identified by Powles.

There is another possible explanation for the discrepancy between the findings of Cullen et al. and this study. It may be that in Cullen et al.'s study more of the students than indicated sought outside assistance but that assistance had not been of a 'critical' nature. The figure from Cullen et al. indicates not only the proportion that sought help, but also comments on the significance of that assistance.

However, in findings of an earlier study completed at an Australian university, Powles (1988) obtained figures closer to those obtained by this author. In that study, 55\% of higher degree research students indicated that they had received no advice from staff in departments outside their own, and $36 \%$ had no help from academic staff other than their own supervisor in their own department. Powles' study broke the contact with academics into two categories, from within and outside the department, and considered advice from staff, a broader grouping than academic staff. However, there is some parallel with the findings of this study that $53 \%$ had not had their proposal reviewed by an academic other than their supervisor or a doctoral consortium facilitator.

There are some advantages of doctoral consortium participation that are not found in systematic expert review, such as the potential for networking, exposure to other research projects and support for common problems. However, many of these strengths are also offered by gatherings of IS researchers, as occur at IS conferences. Moreover, many of these advantages are of only marginal relevance in helping a student focus and develop a research topic. In fact, one participant commented that the doctoral consortium was not the forum for focussing research proposals, 'especially since most participants did not have access to the domain knowledge necessary to assist in focussing. Discussion of method is much more important.'

Most of the comments from students relating to the weaknesses of doctoral consortia are concerned with management issues regarding use of time and grouping students, and the difficulties of obtaining specific and appropriate feedback for each participant. An interesting discrepancy was noted between one advantage of doctoral consortia given by 17 students, 'independent appraisal by peers and researchers' and individual comments that revealed frustration in obtaining specific feedback on an individual's research. The reason for the mismatch may be confusion about the purpose of doctoral consortia, with many students anticipating individual feedback but not obtaining it. Nearly all the drawbacks mentioned would not occur with systematic expert review, where the feedback provided would relate specifically to the relevant student. A participant wrote, 'In my trial doctoral consortium my subject was the focus of attention unlike the consortium where I felt it was not really appropriate within the session group.'

Although specific advantages and disadvantages of systematic expert review were not canvassed in the survey, one obvious disadvantage of systematic expert review when conducted on a large scale is the considerable cost of individual interaction. Another is finding suitable reviewers. Many of the advantages of the doctoral consortium process are also advantages of systematic expert review, for example they both allow academic interaction. However, it was found that some strengths of systematic expert review are not offered by doctoral consortium participation. 


\section{LIMITATIONS OF STUDY AND SUGGESTIONS FOR FUTURE RESEARCH}

The investigation was exploratory. All students had experienced a doctoral consortium of a similar form. However, as not all students had been exposed to systematic expert review and it had not been implemented in a uniform manner, any comparison of the two mechanisms cannot be rigorous. For a more formal evaluation of the mechanisms, the trial of a uniformly administered systematic expert review program is recommended. As more IS doctoral consortia take place, it may be interesting to compare feedback from students related to individual doctoral consortia against variations in how they were run, in order to refine the process.

\section{CONCLUSIONS}

It is clear that doctoral consortia and systematic expert review each have different strengths and weaknesses. Moreover, responses from the students suggest that each of the two mechanisms serves a different purpose and one should not be considered a replacement for the other.

The following conclusions are specific to doctoral consortia:

- Doctoral consortia may function as a preparation for an expert review at a later date.

- Doctoral consortia are discrete events. Students may not wish to enrol in more than one.

- $\quad$ Provision of detailed individual feedback at doctoral consortia may not be appropriate.

Doctoral consortia are most suitable for:

- Social and academic interaction to overcome the isolation of research students

- Networking and support for common problems

- $\quad$ Focussing on methodological and other issues of general interest

- $\quad$ Provision of general advice

The following conclusions are specific to systematic expert review:

- As it is likely that a reviewer's field will be of relevance to the student's project, an expert review is likely to result in targeted advice.

- Systematic expert reviews have a developmental nature in that they place emphasis on the process of change. Such an emphasis may lead to an increased number of iterations of the proposal, and as a result, greater refinement in its focus and quality.

- Comments of reviewers will validate reservations or the confidence of a student or supervisor/s regarding a proposal and its viability.

Systematic expert review is most suitable for:

- $\quad$ Provision of detailed feedback to the student

- Helping to focus a research proposal

- Building ongoing research relationships with experts other than the student's supervisor/s

Although some students had arranged expert review of their proposals, it was found that systematic expert review was not undertaken by the majority of the students who participated in two IS doctoral consortia. A range of other mechanisms were used to focus a research proposal, but none were considered as highly as participation in a doctoral consortium or external review. Students who had been involved in both procedures considered systematic expert review to be the most valuable mechanism for focussing an IS PhD research project.

The author is currently a member of an advisory group assisting the Chair of the Doctoral Consortium for the 7th Australasian Conference on Information Systems.

\section{RECOMMENDATIONS}

Although the following recommendations have been derived from a study set within an IS context, they can be applied to the task of focussing a post-graduate research degree in most disciplines. The following recommendations are directed towards organisers of doctoral consortia and supervisors of Australian postgraduate research students.

- Recognition needs to be given to the special requirements of Australian post-graduates in determining the scope and approach of their project when compared with some other 
international post-graduate research programs. Strategies designed to overcome such difficulties, such as those evaluated in this study, need to be considered.

- Doctoral consortia are recommended for research students early in enrolment for exposure to broad methodological issues and to establish networks, before or at the time of writing a project proposal.

- After a student has developed a proposal, systematic expert review is the best mechanism for refinement of the proposal through expert feedback.

- Systematic expert review is of particular value for students in universities with small IS establishments or in isolated locations.

- To ensure a match between the aims of the students and organisers of a doctoral consortium, students need to be made aware of the emphasis of the doctoral consortium, and be advised that detailed individual feedback on their research proposal may not be possible.

- Doctoral consortium organisers need to allow students some choice in the most relevant peer group to join for discussion.

- Doctoral consortium organisers need to allow students some choice in which facilitator sessions to join, to ensure that the background and interests of the facilitator are the most relevant to the student's work.

- Doctoral consortium organisers need to provide for input from students with regard to discussion topics to ensure relevancy of the program.

\section{REFERENCES}

Conrad, L. (1991) The Doctoral Consortium: A cross-institutional approach to supplementing postgraduate research supervision, HERDSA News, Vol 13, No 2, pp 6-8.

Cullen, D.J., Pearson, M., Saha, L.J. \& Spear, R.H. (1994) Establishing Effective PhD Supervision, Department of Employment, Education and Training, Canberra: Australian Government Publishing Service.

Farhoomand, A.R. (1992) Scientific Progress of Management Information Systems, in R. Galliers (ed.) Information Systems Research: Issues, Methods and Practical Guidelines, Oxford: Blackwell Scientific Publications.

Gable, G.G. \& Clarke, R.A. (1995) 1996 Asia Pacific Directory of Information Systems Researchers, Brisbane: Information Systems Management Research Concentration, Queensland University of Technology.

Galliers, R. (1992) Choosing Information Systems Research Approaches, in R. Galliers (ed.) Information Systems Research: Issues, Methods and Practical Guidelines, Oxford: Blackwell Scientific Publications.

Higher Education Council (1990), Higher Education Courses and Graduate Studies, Canberra: Australian Government Publishing Service.

Jick, T.D.(1983) Mixing Qualitative and Quantitative Methods: triangulation in action, in J. Van Maanen (ed.) Qualitative Methodology, Beverly Hills: Sage Publications.

Keen, P.G.W. (1991) Relevance and Rigour in Information Systems Research: Improving Quality, Confidence, Cohesion and Impact, in H.-E. Nissen, H.K. Klein and R.A. Hirschheim (eds.) Information Systems Research: Contemporary Approaches and Emergent Traditions, Proc. IFIP TC8/WG 8.2 Working Conference, Dec. 1990, Amsterdam: North-Holland.

Locke, L. \& Spirduso, W. (1976) Proposals that Work, a Guide for Planning Research, New York: Teachers College Press, Colombia University.

Miller, D.M. (1993) MIS as a Discipline: A Structured Definition, SIGCSE Bulletin, Vol 25, No 4, pp 27-32.

Mitchell, J. C. (1983) Case and Situation Analysis, Sociological Review, Vol 312, No 2, pp 186-211.

Parry, S. and Hayden, M. (1994) Supervising Higher Degree Research Students; An Investigation of Practices Across a Range of Academic Departments, Canberra: Department of Employment, Education and Training, Australian Government Publishing Service.

Powles, M. (1988) Know Your PhD Students and How to Help Them, Melbourne: Centre for the Study of Higher Education, University of Melbourne.

Roscoe, J.T. (1975), Fundamental Research Statistics for the Behavioral Sciences, 2nd edn, New York: Holt, Rinehart \& Winston Inc.

Shanks, G., Rouse A. \& Arnott, D. (1993) A Review of Approaches to Research and Scholarship in Information Systems, Melbourne: Working Paper Series 3/93, Monash University. 


\section{ACKNOWLEDGEMENTS}

The author would like to thank Dr Chris Keen, Associate Professor Glenn Lowry and members of the Information Systems Group of the University of Tasmania, and Dr Pauline O'Connor for their valuable comments on the draft of this paper. 